\title{
Review
}

\section{Cardiac Dysautonomia in Huntington's Disease}

\author{
Mads Abildtrup ${ }^{\mathrm{a}, *}$ and Michael Shattock ${ }^{\mathrm{b}, *}$ \\ a School of Medicine, King's College London, Guy's Campus, UK \\ ${ }^{\mathrm{b}}$ Professor of Cellular Cardiology, Cardiovascular Division, The Rayne Institute, London, UK
}

\begin{abstract}
Huntington's disease is a fatal, hereditary, neurodegenerative disorder best known for its clinical triad of progressive motor impairment, cognitive deficits and psychiatric disturbances. Although a disease of the central nervous system, mortality surveys indicate that heart disease is a leading cause of death. The nature of such cardiac abnormalities remains unknown. Clinical findings indicate a high prevalence of autonomic nervous system dysfunction - dysautonomia - which may be a result of pathology of the central autonomic network. Dysautonomia can have profound effects on cardiac health, and pronounced autonomic dysfunction can be associated with neurogenic arrhythmias and sudden cardiac death. Significant advances in the knowledge of neural mechanisms in cardiac disease have recently been made which further aid our understanding of cardiac mortality in Huntington's disease. Even so, despite the evidence of aberrant autonomic activity the potential cardiac consequences of autonomic dysfunction have been somewhat ignored. In fact, underlying cardiac abnormalities such as arrhythmias have been part of the exclusion criteria in clinical autonomic Huntington's disease research. A comprehensive analysis of cardiac function in Huntington's disease patients is warranted. Further experimental and clinical studies are needed to clarify how the autonomic nervous system is controlled and regulated in higher, central areas of the brain - and how these regions may be altered in neurological pathology, such as Huntington's disease. Ultimately, research will hopefully result in an improvement of management with the aim of preventing early death in Huntington's disease from cardiac causes.
\end{abstract}

Keywords: Huntington's disease, dysautonomia, heart disease, cardiac death, arrhythmias, heart rate variability, BDNF

\section{INTRODUCTION}

Huntington's disease (HD) is an inherited, progressive neurodegenerative disorder that results from an expanded CAG triplet repeat sequence within the huntingtin gene [1]. It is found throughout all racial groups but shows highest prevalence in the Western world, where about 7-10 individuals per 100,000 are affected [2]. Clinically, HD is characterised by progressive motor impairment, cognitive deficit, and psychiatric

\footnotetext{
*Correspondence to: Mads Abildtrup, School of Medicine, King's College London, Guy's Campus, Hodgkin Building Room G72W, SE1 1UL, UK. Tel.: +44 207848 6060; +44 785596 9689; E-mail: mads.abildtrup@kcl.ac.uk; Michael Shattock, Professor of Cellular Cardiology, Cardiovascular Division, The Rayne Institute, 4th Floor, Lambeth Wing, St Thomas' Hospital, London SE1 7EH, UK. Tel.: +44 207188 0945; +44 797363 3753; Fax: +44 207188 0970; E-mail: michael.shattock@kcl.ac.uk.
}

symptoms, most likely as a result of neuronal dysfunction and neuronal apoptosis [3-5]. In most patients HD becomes symptomatically detectable between 30 and 40 years of age, although the disorder can manifest at anytime between infancy and senescence [2, 6, 7]. There is currently no cure or effective modifying treatment for HD, and death usually occurs 15-20 years after clinical onset [8].

Although primarily a disease of the central nervous system, recent research has revealed a variety of abnormalities in peripheral tissues or organs in patients with HD [9, 10]. Whether these defects are a direct consequence of peripherally expressed mutant huntingtin protein, or secondary to either a general decline in health or the onset of neurological dysfunction, is yet to be fully understood. Interestingly, a review of available epidemiological and research data indicates that heart disease is the second most common cause of death in 
patients with HD, following pneumonia [11-17]. Cardiac failure is implicated in about $30 \%$ of HD patients, in contrast to less than $2 \%$ of age-matched non-HD patients in the general population [10, 18, 19]. Progressive cardiac dysfunction has also been reported in the transgenic mouse models of HD [20-23]. Nonetheless, the mechanisms of cardiac pathophysiology in HD patients remain unknown.

Transgenic HD mice have recently been studied looking for evidence of cardiac abnormalities associated with the mutant huntingtin expression. Poly-Q aggregate pathology has been identified in R6/2 mice and in the HdhQ150 knock-in model. Mihm et al. [20] found significant levels of mutant huntingtin aggregation in the nucleus and mitochondria of cardiomyocytes, which was associated with modified mitochondrial structure and myocardial atrophy in the R6/2 mouse. Left ventricular dilatation and contractile dysfunction was reported and cardiac output reduced by $50 \%$ by 12 weeks of age compared to controls [20]. In addition, generation of mice with cardiomyocyte-specific expression of poly-Q preamyloid oligomers under the control of the $\alpha$-myosin heavy chain promotor lead to protein aggregate formation, necrosis, cardiac dilation, and reduced lifespan [21]. Even though these findings suggest that heart disease in HD could be a result of intrinsic cardiomyocyte dysfunction, one should be cautious in interpreting these results. The cardiac pathophysiology may be due to non-physiological levels of poly-Q, resulting from the over-expression of the protein. Thus, these transgenic mouse models might not directly mimic the situation in human HD. Indeed, in studies of the R6/1 mouse, a model displaying less aggressive and slower onset of HD symptoms, the cardiac phenotype has shown no overt histological abnormalities [23]. Moreover, there is no data to date showing expression of mutant huntingtin in the human heart. This might, of course, be simply due to the lack of post mortem specimen available for analysis. Further study of the possible cardiotoxic entities of mutant huntingtin in human HD tissue is warranted.

Clinical data also suggest that profound autonomic nervous system (ANS) dysfunction often accompanies $\mathrm{HD}$, and this might be associated with widespread pathology of the central autonomic network [9, 24, 25]. It has thus been suggested that aberrant activity of the ANS in HD plays a role in the increased risk of succumbing to cardiac events $[10,26,27]$. The potential cardiac consequences and possible mechanisms of ANS dysfunction in HD patients have, however, received little attention.
In this brief review, we discuss the current knowledge of cardiac autonomic dysfunction in clinical and experimental models of HD. By drawing evidence from recent data within the field of HD, and other neurocardiology studies, we provide a possible explanation of the mechanisms of neurocardiac abnormalities, as well as cardiac causes of death in HD.

\section{CARDIAC DYSAUTONOMIA IN HUNTINGTON'S DISEASE PATIENTS}

Autonomic dysfunction frequently accompanies HD. Patients report of significantly more gastrointestinal, urinary, sexual and cardiovascular problems relative to age- and sex-matched controls [24]. Accordingly, clinical HD studies using various testing methods such as heart rate variability (HRV) analyses have revealed aberrant activities of both the sympathetic and parasympathetic branches of the ANS. Early data demonstrated hypofunction of the ANS in advanced HD patients [28, 29]. Using classical HRV bedside tests, Sharma and colleagues concluded from their investigation of $22 \mathrm{HD}$ patients that autonomic neurocardiac regulation was characterised by an imbalance between sympathetic and parasympathetic control of the heart [29]. Similarly, decreased cardiovagal activity was found in the middle stages of HD indicated by a decline in HRV at rest and during deep respiration, both resembling vagus-dominant autonomic test conditions [26]. It is worth mentioning here that patients taking medication known to possess an anticholinergic effect were still enrolled in these studies, and this might have had an impact on the results. Spectral analysis of HRV, in contrast, advocates increased sympathetic activity in presymptomatic HD mutation carriers and mildly disabled HD patients [30]. This was in line with the clinical symptoms indicative of sympathetic dysfunction, such as orthostatic dizziness and tachycardia. Bar et al. [27] predominantly found parasympathetic dysfunction in their study of mid-stage HD patients compared with healthy subjects, with similar findings reported in a group of advanced HD patients [30].

Although the clinical data above is implying that cardiac autonomic control might become deregulated in $\mathrm{HD}$, the evidence should, however, be interpreted with caution. First, the methods of the available studies were such that onset and timing of autonomic dysregulation was hard to establish and generally lacked specificity and sensitivity. Second, ANS activity was evaluated indirectly by analysis of HRV parameters on short-term 
(1-10 min) electrocardiographic recordings in subjects commonly presenting with an arbitrary psychological state. Despite the HRV technique being a popular noninvasive method of testing cardiac ANS activity, this analysis has significant limitations in its interpretation, and its accuracy is highly controversial $[32,33]$. In addition, the power spectrum HRV analysis only measures changes in ANS discharge and not the absolute intensity of sympathetic and parasympathetic activity. Detailed reviews on this matter have been published elsewhere [33-36].

It has been suggested that sympathovagal dysautonomia in favour of sympathetic drive could possibly result in fatal cardiac arrhythmias and/or cardiac failure and could, in turn, account for the unknown nature of heart related mortality in HD [26, 27, 37]. In general, augmented sympathetic outflow and/or decreased vagal activity is considered to be pro-arrhythmic, as evidenced by a variety of experimental models $[38,39]$. A reduction in HRV and enhanced sympathetic activity is associated with increased risk of cardiovascular morbidity and mortality, and sudden cardiac death in even apparently healthy subjects [40-44].

No study has investigated the plausible cardiac consequences of dysautonomia in the HD patient population. In fact, underlying cardiac abnormalities such as arrhythmias have been part of the exclusion criteria in clinical autonomic HD research. An in dept study of cardiac function needs to be undertaken.

\section{FINDINGS FROM TRANSGENIC MICE}

Over the years, a variety of animal models for the study of HD have been developed. Transgenic mice expressing mutant forms of the huntingtin protein are the most commonly used models in HD research and are important for examining the pathophysiology of the disease. However, no mouse model mimics the human condition in its entirety, nor displays the degree of neurodegeneration that occurs in humans (recently reviewed in [45]). The inherent differences between human HD and experimental models must be kept in mind when interpreting any results. Nevertheless, each model supplies relevant data for the understanding of HD mechanisms.

Recently, ANS dysfunction has been reported in several transgenic lines [23, 46-48]. In the BACHD model (transgenic mouse expressing 97 glutamine repeats [49]), significant increased blood pressure and heart rate, together with a blunted baroreceptor reflex response was observed when compared to wild type controls [47]. The baroreflex plays a dominant role in maintaining overall circulatory homeostasis and short-term regulations of blood pressure by dynamic autonomic modulation of cardiac output and total peripheral resistance $[50,51]$. Thus, baroreflex sensitivity is often used as a marker in the assessment of autonomic neural control of the heart. Dysregulation of this reflex may, in the long run, have a deleterious effect on cardiac function [51]. Human studies testing the baroreceptor reflex in HD have, nonetheless, generated mixed results [52, 27-29].

Telemetry recordings from different HD models including BACHD, R6/2 and R6/1 have indicated abnormalities in sleep patterns, body temperature and heart rate changes over a 12-hour light/dark cycle, and in circadian rhythm measured during 12-hour dark/dark conditions [23, 46, 47, 53]. Similar to findings in HD patients, BACHD mice displayed a decrease in HRV [47]. Compromised function of the ANS was further evident by increase in heart rate and body temperature, loss of day/night differences in the PR interval (time taken of the electrical impulse from sinus node to the atrioventricular node), as well as the decrease in the amplitude of rhythmicity in heart rate and body temperature [47].

In a recent comprehensive study, the neurocardiac phenotype in R6/1 transgenic mice, covering early (3 months old) to advanced ( 7 months old) stages of HD was investigated [23]. The data indicates pronounced cardiac ANS malfunction from an early HD phase. R6/1 mice displayed continuous long-term cardiac sympathetic enhancement as evidenced by increased heart rate levels and significant raised plasma levels of noradrenaline, along with a reduced content of cardiac noradrenaline at 7 months old [23]. The intra-neuronal metabolite of noradrenaline, dihydroxyphenylethylene glycol was, however, the same in R6/1 mice and controls, suggesting neuronal reuptake of noradrenaline was not altered [23]. Interestingly, similar alterations have been documented in the context of cardiac failure [54, 55]. Analysis of 24-hour telemetry ECG recordings in R6/1 mice revealed unstable and chaotic heart rhythms with a variety of arrhythmias including atrial flutter, atrial fibrillation, supra-ventricular and ventricular premature beats, episodes of ventricular tachycardia and, even, sudden cardiac death (Fig. 1A) [23]. Of note, heart rate variations were attenuated by administration of atropine, suggesting the erratic heart variations were due to augmented parasympathetic activity [23]. A hyperactive parasympathetic nervous system has also been reported in human HD, particularly in patients with juvenile HD [56]. 
A:

Sinus arrhythmias and A-V block
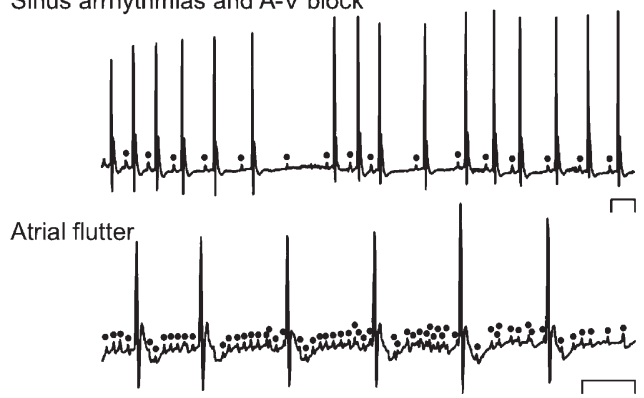

Paroxismal AF

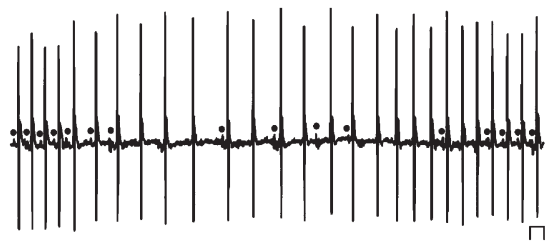

VPBs

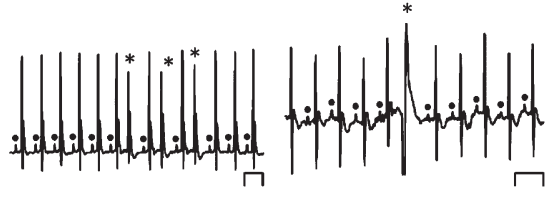

VT

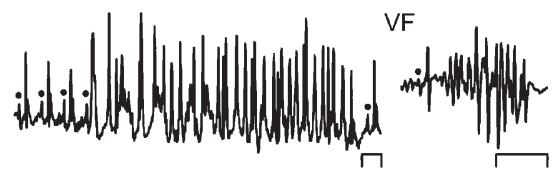

B:

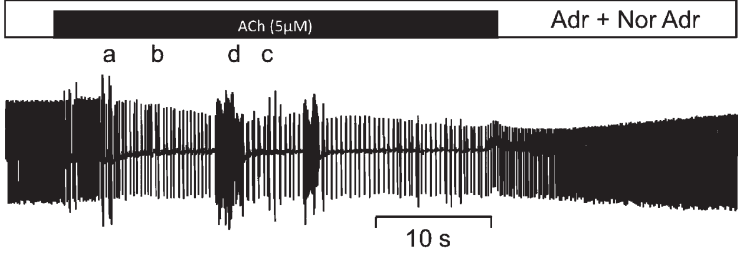

Sinus arrhythmias, A-V block and ventricular salvos (a)

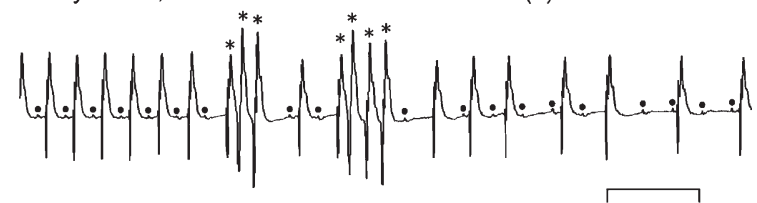

A-V block (b)

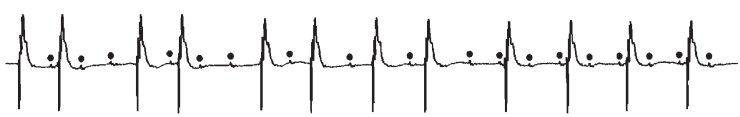

VT/torsade de pointes (d)

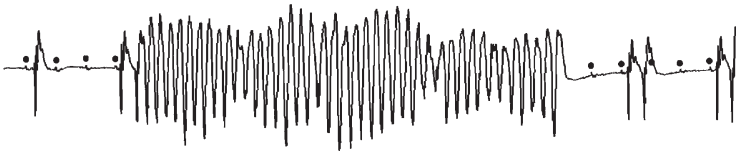

Fig. 1. Similarity of arrhythmias recorded from R6/1 mice (A) and during autonomic conflict in an isolated rat heart (B). Panel A shows ECGs recorded by telemetry from R6/1 mice. Arrhythmias include sinus arrhythmias (note absence of a consistent P-R interval), A-V block, atrial flutter, paroxysmal atrial fibrillation (AF: as indicated by the lack of $\mathrm{P}$ waves, unstable baseline and irregular R-R intervals) and re-entrant arrhythmias in the form of both ventricular tachycardia (VT) and ventricular fibrillation (VF). Panel B shows similar arrhythmias recorded via an epicardial electrode in a Langendorff-perfused rat heart subjected to an autonomic conflict protocol. This protocol consisted of perfusion with a constant background of adrenaline $(75 \mathrm{nM})$ and noradrenaline $(313 \mathrm{nM})$ on which a 1 min period of acetylcholine $(\mathrm{ACh}$ : $5 \mu \mathrm{M})$ was superimposed as indicated. The top trace shows a slow time-base recording and the arrhythmias recorded at the points marked a-d on this trace are expanded below. Solid circles indicate $\mathrm{P}$ waves and asterisks indicate ventricular premature beats (VPBs). The time-bars on the expanded ECG traces are $500 \mathrm{msec}$. Arrhythmias are classified according to the Lambeth Conventions II [131]. Panel A is redrawn from reference 23 and Panel B is redrawn from reference 58, by permission.

The findings of augmented sympathovagal activity leading to cardiac arrhythmias and sudden death provide new clues for possible neurocardiac causes of death in patients with HD. Similarly hyperactivity of sympathetic and parasympathetic activity is thought to play a role in sudden cardiac death after ischaemic stroke [57]. Autonomic conflict, i.e. coincidental overactivity of both limbs of the ANS, can also lead to cardiac arrest as evident by investigation of sudden death by cold water immersion [58-60]. Data from ambulatory animals have illustrated that dual sympathovagal discharges can contribute to development and maintenance of atrial flutter and paroxysmal atrial tachycardia [61-63]. Furthermore, it was recently reported that superimposing pulses of acetylcholine (to simulate burst of parasympathetic activity) on a background of moderate sympathetic drive (adrenaline-noradrenaline administration) in isolated Langendorff-perfused rat hearts produce an array of arrhythmias, such as AV block, bradycardia, tachycardia, ventricular premature beats, and a rhythm resembling life-threatening polymorphic ventricular tachycardia - torsades de pointes (Fig. 1B) [58]. The similarities between the traces in Fig. 1A and B are striking. Ex vivo isolated Langendorff investigation of $\mathrm{R} 6 / 2$ mice hearts has also demonstrated abnormalities 
of cardiac function in form of impaired myocardial contractility and relaxability, and attenuated left ventricular developed pressure and coronary flow rate [22]. Autonomic function was, however, not investigated.

\section{HUNTINGTON'S DISEASE BRAIN PATHOLOGY AND CARDIAC DYSAUTONOMIA}

The regulation of the heart by the ANS has been widely discussed in the literature. While classical neurocardiological research on central control and regulation of cardiac functions has generally focused on parasympathetic and sympathetic circuits at the spinal and brainstem level, more recent evidence has demonstrated cardiac autonomic regulation to be under widespread cortical and subcortical influence [64, 65]. Clinical and experimental observations strongly suggest autonomic control by the prefrontal cortex, bilateral insular cortex, anterior cingulate gyrus, amygdala, and hypothalamus [66-68]. However, direct evidence linking brain pathology in HD to cardiac autonomic dysfunction is sparse. Investigations using autonomic cardiovascular challenge tests, cognitive stress (mental arithmetic) and cold pressor tests, to challenge higher-ordered ANS centres suggest dysfunction in these regions in both pre- and early symptomatic HD patients [37, 69]. These tests have, however, low sensitivity and specificity in detecting autonomic malfunction and have a variable intersubject response [70]. Several brain regions associated with regulation of cardiac autonomic control have been found affected in the disorder [8, 71-75].

New results from the TRACK-HD study indicate significantly greater progressive grey-matter, white-matter, whole-brain, and regional atrophy in pre-manifest and early HD groups than in control groups [76]. This is in line with other data using imaging modalities and a recent coordinate-based meta-analysis for structural changes in HD based on voxel-based morphometry [77] - all demonstrating neurodegeneration in the main the components of the central autonomic network [77-80]. The insular cortex is an important region in controlling sympathovagal tone [68]. Both right and left insular lesions, often as a result of a stroke involving the middle cerebral artery, have been associated with cardiac autonomic derangement, arrhythmias and an increased risk of cardiac death [81-83]. Moreover, animal models using electrical stimulation, together with clinical data and positron emission tomography neuroimaging suggest a lateralisation of cardiac regulation in this brain region - with right insular region chiefly controlling sympathetic tone, and parasympathetic tone mediated by the left insular [57, 67, 84-88]. A noteworthy observation is the report of insular atrophy predominating in the left hemisphere in HD patients which, to some extent, may account for the sympathetic dominance and parasympathetic withdrawal demonstrated by HRV analysis in HD patients [89-91].

Known to have crucial neurotrophic functions in both the embryonic and adult brain, brain-derived neurotrophic factor (BDNF) also appears to play a major part in ANS regulation of heart rate and cardiovascular health. Humans displaying polymorphism (Val66Met) in the BDNF gene, leading to attenuated BDNF secretion, have sympathovagal imbalance [92]. BDNF and its receptor TrkB are expressed in higher cardiac control regions such as amygdala, frontal cortex and hypothalamus, along with central autonomic nuclei of the brainstem [93-97]. It was recently reported that BDNF expression protects against cardiac dysfunction via a central nervous system-mediated pathway [88]. Interestingly, levels of BDNF in the striatum, cortex, and brainstem of HD patients are reduced [99, 100]. An in vitro model of $\mathrm{HD}$ also suggests that aberrant expression of BDNF perturbs microcircuitry and signalling in the cerebral cortex, and overexpression of BDNF in the striatum ameliorates HD phenotypes in R6/1 mice [101, 102]. HD mice (N171-82Q) exhibit attenuated expression of BDNF and TrkB in brainstem cardiovascular nuclei, and also elevated heart rates and dysregulation of heart rates during restraint stress [48]. Intracerebroventricular administration of BDNF decreases and restores heart rates to wildtype levels. Future studies of HD should investigate BDNF signalling in higher autonomic cardiac control sites.

Although incompletely understood, neuronal dysfunction and neuronal cell death are also likely to be causing the neuropsychiatric symptoms associated with HD. The possible implication of psychiatric disturbances on cardiac health should not be ignored. Severe depression, anxiety, irritability, and anger are extremely common in HD patients [2, 103, 104]. Mounting evidence indicates that, in particular, depression and anxiety are risk factors for cardiac events such as coronary heart disease, atrial and ventricular fibrillation, and sudden cardiac death [105-107]. While behavioural risk factors may account for this correlation, autonomic dysregulation has been suggested to play an important role in the increased risk for cardiovascular events in patients with depressive and anxiety disorders [108]. 
From a broader perspective it is interesting to note that cardiac dysautonomia is a common feature of neurodegenerative disorders. Orthostatic hypotension is a frequent characteristic of parkinsonian disorders such as Parkinson's disease and multiple system atrophy and autonomic impairment has also been reported in a variety of neurodegenerative dementias [109-113]. Recent studies have revealed a high prevalence of cardiac ectopy associated with supine hypertension, baroreflex-cardiovagal failure, and baroreflexsympathoneural failure in patients with chronic autonomic failure [114, 115] Parkinson's disease patients have also been reported to have increased mortality due to heart disease with autonomic dysregulation being suggested as a possible contributing factor [116-118].

\section{DYSAUTONOMIA AND CARDIAC MORTALITY IN HUNTINGTON'S DISEASE - POSSIBLE MECHANISMS}

The data discussed here suggest that cardiac autonomic control can become deregulated in HD. A direct link between ANS dysfunction and the cause of death in HD patients remains however tenuous. Nonetheless, it could be speculated that impairment of central autonomic cardiac control may lead to dysautonomia and autonomic conflict and, in turn, trigger heart rate instability and cardiac arrhythmias which may ultimately be lethal. Moreover, the toxic mutated huntingtin protein may cause in vivo cardiomyocyte malfunction of cardiac efficiency and perturb intracellular signalling and protein expression - all which could destabilise cardiac electrophysiology and therefore increase the susceptibility to cardiac death during autonomic imbalance (Fig. 2).

Different theories could explain the arrhythmogenic mechanism of dysautonomia, and the substrate for arrhythmias could be enhanced by various predisposing factors in HD. Sympathetic and parasympathetic stimulation, acting through beta-adrenergic and muscarinic receptors respectively, induce their effect by causing electrophysiological changes in the myocardium. Sympathetic stimulation and its resulting increase in heart rate (i.e. the R-R interval of the ECG decreases) will lead to a reduction in action potential duration and hence QT interval. In contrast, the action potential and QT interval are prolonged as the heart rate slows. Thus, on a background of increased sympathetic stimulation, co-incident parasympathetic overactivity could lead to a fair imitation of QT/RR hysteresis; that is the heart rate increases but with no accompa- nying decrease of the QT interval. Indeed, evidence implies that the failure of the QT interval to decrease in response to a rise in heart rate may be a feature of vagal activation [119-121]. A prolonged action potential conjoined with an increased heart rate may cause myocardial cells to be depolarised for a larger fraction of the cardiac cycle. Together with a rate-dependent rise in calcium influx, this will increase the probability of calcium overload - an established mechanism giving rise to membrane oscillations, ventricular automaticity and arrhythmias [122].

Patients with long QT syndrome (a congenital disorder with mutations in a specific potassium channel, leading to prolonged repolarisation) are highly susceptible to arrhythmias, torsades de pointes and are at increased risk for sudden cardiac death [123]. Delaying repolarisation experimentally can cause a 57-fold reduction in the diastolic interval (TQ interval) and a marked increase in the QT/TQ ratio (ECG restitution) during heart rate acceleration with sympathetic stimulation using isoproterenol challenges [124]. In other words, the ability of the heart to recover (e.g. for oxygenation and return of ion kinetics to normal state) from one beat to the next is significantly reduced, making it vulnerable to unstable re-entry and arrhythmias. Of interest, several drugs implicated in prolonging the QT interval may predispose HD patients to lethal arrhythmias. These drugs include certain antipsychotics (eg, chlorpromazine, haloperidol, thioridazine, mesoridazine) and antidepressants drugs (eg, amitriptyline, mirtazapine, citalopram), antibiotics (eg, erythromycin, clarithromycin), and gastrointestinal prokinetics (eg, cisapride, domperidone) [125].

The heterogeneity of both pre- and postsynaptic autonomic cardiac innervation may also exacerbate the pro-arrhythmic potential of dysautonomia. In normal human hearts, and those of other mammals, parasympathetic nerves and muscarinic receptors are largely located in the atria and nodel tissue. Conversely, innervation of the ventricles is predominantly by sympathetic neurons, displaying a gradient morphology with the highest density of nerve endings found at the base, decreasing to the lowest levels at the apex [126-128]. Under pathological and extreme conditions where the ANS becomes dysregulated, these regional variations may be in favour of compounding electrical inhomogeneity and trigger arrhythmias [58].

Lastly, long-standing persistent arrhythmia is a wellknown cause of heart failure and cardiomyopathy and, in most cases, sudden unexpected death is caused by fatal cardiac arrhythmias [122, 129]. Any pre-existing 


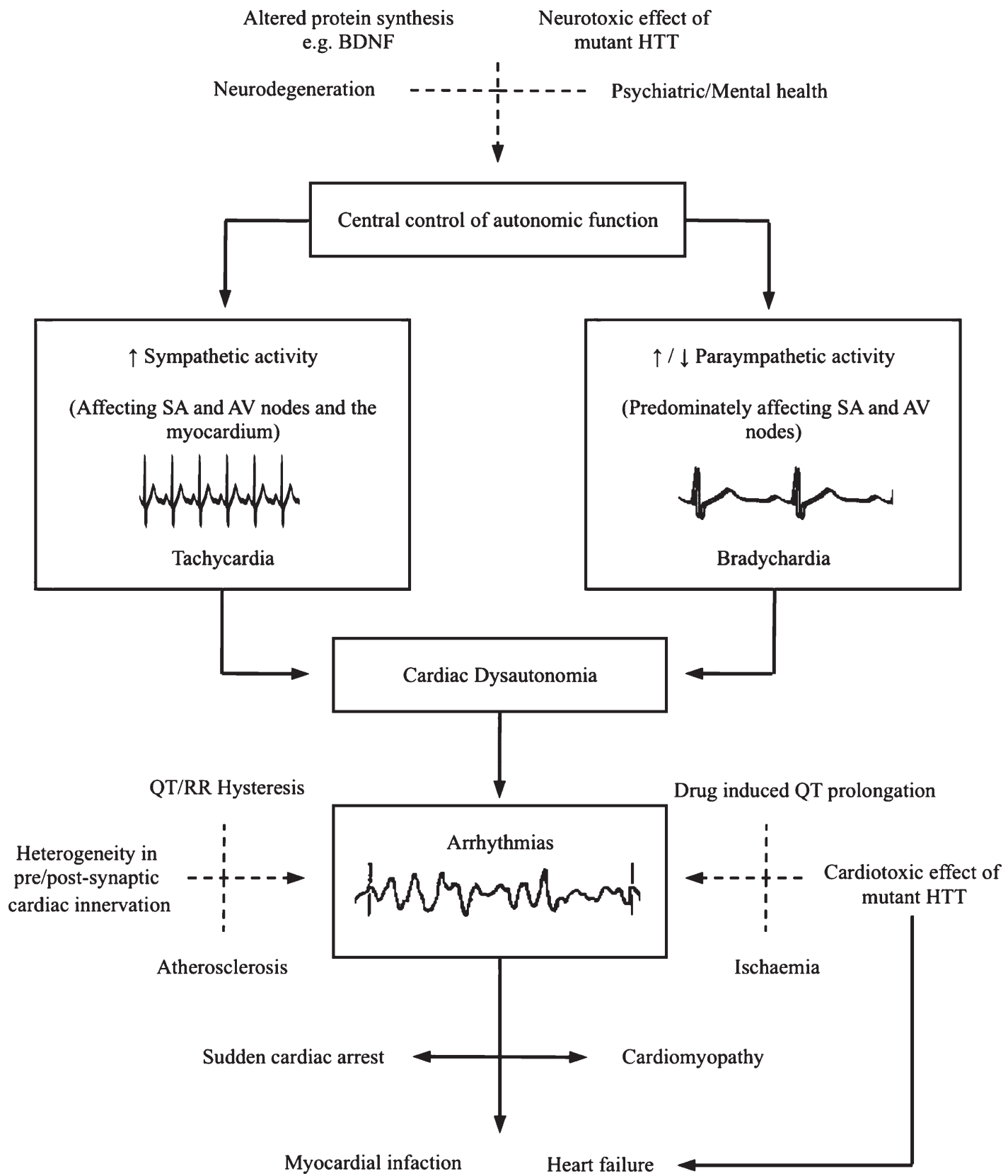

Fig. 2. Possible mechanisms of cardiac mortality from dysautonomia in Huntington's disease. The central autonomic network is likely to be affected by pathological processes and psychiatric disturbances in Huntington's disease leading to dysfunction in both limbs of the autonomic nervous system. Altered and conflicting inputs to the heart can result in arrhythmias causing cardiac dysfunction and could, ultimately, be lethal. Various predisposing factors may enhance the arrhythmogenic potential of dysautonomia. Cardiomyocyte dysfunction due to intrinsic mutant huntingtin (HTT) expression might also induce abnormalities and could directly, or in combination with altered autonomic tone, be detrimental to cardiac health. Adapted from reference 58.

coronary atherosclerotic changes or myocardial injury are also likely exacerbate arrhythmias during cardiac autonomic dysfunction. Indeed, evidence supports the role of autonomic imbalance in neurogenic myocardial injury $[57,130]$.

\section{CONCLUSION AND FUTURE RESEARCH}

Despite the evidence of cardiac dysautonomia in $\mathrm{HD}$, the complex interactions between the brain and the heart are incompletely understood. The cause of 
cardiac associated death in HD is likely to be multifactorial. Further research is needed to fully elucidate the pathophysiology and the involvement of ANS dysfunction. A detailed analysis of cardiac function in HD patients is warranted, preferably using $24 \mathrm{~h}$ Holter monitoring of ECG. A better understanding of cardiac electrophysiology and its interaction with sympathovagal activity is necessary. Additionally, a clarification of how the ANS is controlled and regulated in higher central areas of the brain - and how these regions may be altered by pathology - remains crucial. Functional neuroimaging and spatialtemporal mapping should allow for a better characterisation of key areas of autonomic control and alteration in HD. From a clinical perspective, this knowledge should help to identify the causative factors that make the HD heart vulnerable to cardiac events, and would also aid the development of therapeutic approaches with the aim of preventing early death from cardiac causes. Finally, a better understanding of the link between HD brain pathology and cardiac dysautonomia would also increase our knowledge of the neurogenic connections between the brain and heart.

\section{CONFLICTS OF INTEREST}

No conflicts of interest.

\section{REFERENCES}

[1] Bates GP. History of genetic disease: The molecular genetics of Huntington disease - a history. Nat Rev Genet. 2005;6:766-73.

[2] Walker FO. Huntington's disease. Lancet 2007;369:218-28.

[3] Saudou F, Finkbeiner S, Devys D, Greenberg ME. Huntingtin acts in the nucleus to induce apoptosis but death does not correlate with the formation of intranuclear inclusions. Cell 1998;95:55-66.

[4] Munoz-Sanjuan I, Bates GP. The importance of integrating basic and clinical research toward the development of new therapies for Huntington disease. J Clin Invest. 2011;121:476-83.

[5] Bano D, Zanetti F, Mende Y, Nicotera P. Neurodegenerative processes in Huntington's disease. Cell Death Dis. 2011;2:e228.

[6] Andrew SE, Goldberg YP, Kremer B, Telenius H, Theilmann J, Adam S, Starr E, Squitieri F, Lin B, Kalchman MA, Graham RK, Hayden MR. The relationship between trinucleotide (CAG) repeat length and clinical features of Huntington's disease. Nat Genet. 1993;4:398-403.

[7] Snell RG, MacMillan JC, Cheadle JP, Fenton I, Lazarou LP, Davies P, MacDonald ME, Gusella JF, Harper PS, Shaw DJ. Relationship between trinucleotide repeat expansion and phenotypic variation in Huntington's disease. Nat Genet. 1993;4:393-97.

[8] Ross CA, Tabrizi SJ. Huntington's disease: From molecular pathogenesis to clinical treatment. Lancet Neurol. 2011; 10:83-98.
[9] Sassone J, Colciago C, Cislaghi G, Silani V, Ciammola A. Huntington's disease: The current state of research with peripheral tissues. Exp Neurol. 2009;219:385-97.

[10] Van der Burg JM, Bjorkqvist M, Brundin P. Beyond the brain: Widespread pathology in Huntington's disease. Lancet Neurol. 2009;8:765-74.

[11] Chiu E, Alexander L. Causes of death in Huntington's disease. Med J Aust. 1982;1:153.

[12] Conneally PM. Huntington disease: Genetics and epidemiology. Am J Hum Genet. 1984;36:506-26.

[13] Haines JL, Conneally PM. Causes of death in Huntington disease as reported on death certificates. Genet Epidemiol. 1986;3:417-23.

[14] Lanska DJ, Lavine L, Lanska MJ, Schoenberg BS. Huntington's disease mortality in the United States. Neurology 1988;38:769-72.

[15] Sorensen SA, Fenger K. Causes of death in patients with Huntington's disease and in unaffected first degree relatives. J Med Genet. 1992;29:911-14.

[16] Heemskerk AW, Roos RAC. Aspiration pneumonia and death in Huntington's disease. PLoS Curr 2012: doi: 10.1371/currents.RRN1293.

[17] Schonberger SJ, Jezdic D, Faull RLM, Cooper GJS. Proteomic Analysis of the Human Brain in Huntington's Disease Indicates Pathogenesis by Molecular Processes Linked to other Neurodegenerative Diseases and to Type2 Diabetes. Journal of Huntington's Disease 2013;2: 89-99.

[18] Lanska DJ, Lanska MJ, Lavine L, Schoenberg BS. Conditions associated with Huntington's Disease and death. A case control study. Arch Neurol. 1988;45:878-80.

[19] CDC/NCHS, AHA. National Health and Nutrition Examination Study (NHANES III). 1988-94. CDC/ NCHS and the American Heart Association.

[20] Mihm MJ, Amann DM, Schanbacher BL, Altschuld RA, Bauer JA, Hoyt KR. Cardiac dysfunction in the R6/2 mouse model of Huntington's disease. Neurobiol Dis. 2007;25:297-308.

[21] Pattison JS, Sanbe A, Maloyan A, Osinska H, Klevitsky R, Robbins J. Cardiomyocyte Expression of a Polyglutamine Preamyloid Oligomer Causes Heart Failure. Circulation 2008;117:2743-51.

[22] Wood NI, Sawiak SJ, Buonincontri G, Niu Y, Kane AD, Carpenter TA, Giussani DA, Morton AJ. Direct Evidence of Progressive Cardiac Dysfunction in a Transgenic Mouse Model of Huntington's Disease. Journal of Huntington's Disease 2012;1:57-64

[23] Kiriazis H, Jennings NL, Davern P, Lambert G, Su Y, Pang T, Du X, La Greca L, Head GA, Hannan AJ, Du XJ. Neurocardiac dysregulation and neurogenic arrhythmias in a transgenic mouse model of Huntington's disease. J Physiol. 2012;15:1-16

[24] Aziz NA, Anguelova GV, Marinus J, van Dijk JG, Roos RA. Autonomic symptoms in patients and pre-manifest mutation carriers of Huntington's disease. Eur J Neurol. 2010;17:1068-74.

[25] Aziz NA, Ross RA. Autonomic Symptoms in Huntington's Disease - Current Understanding and Perspectives for the Future. Eur Neurol Review. 2010;5:46-48.

[26] Andrich J, Schmitz T, Saft C, Postert T, Kraus P, Epplen JT, Przuntek H, Agelink MW. Autonomic nervous system function in Huntington's disease. J Neurol Neurosurg Psychiatry. 2002;72:726-31.

[27] Bar KJ, Boettger MK, Andrich J, Epplen JT, Fischer F, Cordes J, Koschke M, Agelink MW. Cardiovagal modula- 
tion upon postural change is altered in Huntington's disease. Eur J Neurol. 2008;15:869-71.

[28] Den Heijer JC, Bollen WL, Reulen JP, van Dijk JG, Kramer CG, Roos RA, Buruma OJ. Autonomic nervous function in Huntington's disease. Arch Neurol. 1988;45:309-12.

[29] Sharma KR, Romano JG, Ayyar DR, Rotta FT, Facca A, Sanchez-Ramos J. Sympathetic skin response and heart rate variability in patients with Huntington disease. Arch Neurol. 1999;56:1248-52.

[30] Kobal J, Meglic B, Mesec A, Peterlin B. Early sympathetic hyperactivity in Huntington's disease. Eur J Neurol. 2004; 11:842-48.

[31] Eckberg DL. Sympathovagal balance: A critical appraisal. Circulation 1997;96:3224-32.

[32] Goldstein DS, Bentho O, Park MY, Sharabi Y. Lowfrequency power of heart rate variability is not a measure of cardiac sympathetic tone but may be a measure of modulation of cardiac autonomic outflows by baroreflexes. Exp Physiol. 2011;96:1255-61.

[33] Weimer LM. Autonomic testing: Common techniques and clinical applications. Neurologist 2010;16:215-22.

[34] Heathers JAJ. Sympathovagal balance from heart rate variability: An obituary. Exp Physiol. 2012;97:556.

[35] Nicolini P, Ciulla MM, Asmundis CD, Magrini F, Brugada $P$. The prognostic value of heart rate variability in the elderly, changing the perspective: From sympathovagal balance to chaos theory. Pacing Clin Electrophysiol. 2012;35: 622-38.

[36] Pagani M, Lucini D, Porta A. Sympathovagal balance from heart rate variability: Time for a second round? Exp Physiol. 2012;97:1141-42.

[37] Kobal J, Melik Z, Cankar K, Bajrovic FF, Meglic B, Peterlin $\mathrm{B}$, Zaletel M. Autonomic dysfunction in presymptomatic and early symptomatic Huntington's disease. Acta Neurol Scand. 2010;121:392-99.

[38] Schwartz PJ, Zipes DP. Autonomic regulation of cardiac arrhythmias. In Cardiac Electrophysiology From bench to Bedside, ed. Zipes DP, Jalife J, Saunders WB, Philadelphia, 2004

[39] Ng GA, Brack KE, Patel VH, Coote JH. Autonomic modulation of electrical restitution, alternans and ventricular fibrillation in the isolated heart. Cardiavasc Res. 2007;73:750-60.

[40] Molgaard H, Sorensen KE, Bjerregaard P. Attenuated 24-h heart rate variability in apparently healthy subjects, subsequently suffering sudden cardiac death. Clin Auton Res. 1991;1:233-37.

[41] Algra A, Tijssen JGP, Roelandt JRTC, Pool J, Lubsen J. Heart rate variability from 24-hour electrocardiography and the 2-year risk for sudden death. Circulation 1993;88:18085.

[42] Schwartz PJ. The autonomic nervous system and sudden death. Eur Heart J. 1998;19:72-80.

[43] Huikuri HV, Castellanos A, Myerburg RJ. Sudden death due to cardiac arrhythmias. N Engl J Med. 2001;345:1473-82.

[44] Bayés de Luna A, Elosua R. Sudden Death. Rev Esp Cardiol. 2012;65:1039-52.

[45] Crook ZR, Housman D. Huntington's Disease: Can Mice Lead the Way to Treatment? Neuron 2011;69:423-35.

[46] Kudo T, Schroeder A, Loh DH, Kuljis D, Jordan MC, Roos $\mathrm{KP}$, Colwell CS. Dysfunctions in circadian behavior and physiology in mouse models of Huntington's disease. Exp Neurol. 2011;228:80-90.

[47] Schroeder AM, Loh DH, Jordan MC, Roos KP, Colwell CS Baroreceptor reflex dysfunction in the BACHD mouse model of Huntington's disease. PLoS Curr. 2011;3: RRN1266.

[48] Griffioen KJ, Wan R, Brown TR, Okun E, Camandola S, Mughal MR, Phillips TM, Mattson MP. Aberrant heart rate and brainstem brain-derived neurotrophic factor (BDNF) signaling in a mouse model of Huntington's disease. Neurobiol Aging. 2012;33:1481 e1-1481.e5.

[49] Gray M, Shirasaki DI, Cepeda C, Andre VM, Wilburn B, Lu XH, Tao J, Yamazaki I, Li SH, Sun YE, Li XJ, Levine MS, Yang XW. Full-length human mutant huntingtin with a stable polyglutamine repeat can elicit progressive and selective neuropathogenesis in BACHD mice. J Neurosci. 2008;28:6182-95.

[50] Benarroch EE. The arterial baroreflex: Functional organization and involvement in neurologic disease. Neurology 2008;71:1733-38.

[51] La Rovere MT, Pinna GD, Raczak G. Baroreflex sensitivity: Measurement and clinical implications. Ann Noninvasive Electrocardiol. 2008;13:191-207.

[52] Aminoff MJ, Gross M. Vasoregulatory activity in patients with Huntington's chorea. J Neurol Sci. 1974;21:33-38.

[53] Morton AJ, Wood NI, Hastings MH, Hurelbrink C, Barker RA, Maywood ES. Disintegration of the sleep-wake cycle and circadian timing in Huntington's disease. J Neurosci. 2005;25:157-63.

[54] Kaye DM, Lambert GW, Lefkovits J, Morris M, Jennings G, Esler MD. Neurochemical evidence of cardiac sympathetic activation and increased central nervous system norepinephrine turnover in severe congestive heart failure. J Am Coll Cardiol. 1994;23:570-78.

[55] Himura Y, Felten SY, Kashiki M, Lewandowski TJ, Delehanty JM, Liang CS. Cardiac noradrenergic nerve terminal abnormalities in dogs with experimental congestive heart failure. Circulation 1993;88:1299-1309.

[56] Stober T, Sen S, Burger L. Bradycardia and second-degree AV block: An expression of the dominance of cholinergic activity in the rigid form of Huntington's disease. J Neurol. 1983;229:129-32.

[57] Sörös P, Hachinski V. Cardiovascular and neurological causes of sudden death after ischaemic stroke. Lancet Neurol. 2012;11:179-88.

[58] Shattock MJ, Tipton MJ. 'Autonomic Conflict': A different way to die during cold water immersion? J Physiol. 2012; 590:3219-30.

[59] Tipton MJ, Kelleher P, Golden FS. Supraventricular arrhythmias following breath-hold submersions in cold water. Undersea Hyperb Med. 1994;21:305-13.

[60] Tipton M, Gibbs P, Brooks C, Roiz de Sa D, Reilly T. ECG during the first helicopter underwater escape training (HUET) submersions of novice trainees. Physiological Society Meeting, King's College London. London, UK: Proceedings of the Physiological Society 2009;14:PC24.

[61] Sharifov OF, Fedorov VV, Beloshapko GG, Glukhov AV, Yushmanova AV, Rosenshtraukh LV. Roles of adrenergic and cholinergic stimulation in spontaneous atrial fibrillation in dogs. J Am Coll Cardiol. 2004;43:483-90.

[62] Tan AY, Zhou S, Ogawa M, Song J, Chu M, Li H, Fishbein MC, Lin SF, Chen LS, Chen PS. Neural mechanisms of paroxysmal atrial fibrillation and paroxysmal atrial tachycardia in ambulatory canines. Circulation 2008;118:916-25.

[63] Shen MJ, Choi EK, Tan AY, Lin SF, Fishbein MC, Chen LS, Chen PS. Neural mechanisms of atrial arrhythmias. Nat Rev Cardiol. 2011;9:30-39.

[64] Cechetto DF, Shoemaker JK. Functional neuroanatomy of autonomic regulation. Neuroimage 2009;47:795-803. 
[65] Thayer JF, Lane RD. Claude Bernard and the heart-brain connection: Further elaboration of a model of neurovisceral integration. Neurosci Biobehav Rev. 2009;33:81-88.

[66] Kimmerly DS, O'Leary DD, Menon RS, Gati JS, Shoemaker JK. Cortical regions associated with autonomic cardiovascular regulation during lower body negative pressure in humans. J Physiol. 2005;569:331-45.

[67] Pasquini M, Laurent C, Kroumova M, Masse I, Deplanque D, Leclerc X, Bordet R, Leys D. Insular infarcts and electrocardiographic changes at admission: Results of the PRognostic of Insular CErebral infarctS Study (PRINCESS). J Neurol. 2006;253:618-24.

[68] Nagai M, Hoshide S, Kario K. The insular cortex and cardiovascular system: A new insight into the brain-heart axis. J Am Soc Hypertens. 2010;4:174-82.

[69] Melik Z, Kobal J, Cankar K, Strucl M. Microcirculation response to local cooling in patients with Huntington's disease. J Neurol. 2012;259:921-28.

[70] Freeman R. Assessment of cardiovascular autonomic function. Clin Neurophysiol. 2006;117:716-30.

[71] Rosas HD, Hevelone ND, Zaleta AK, Greve DN, Salat DH, Fischl B. Regional cortical thinning in preclinical Huntington disease and its relationship to cognition. Neurology 2005;65:745-47.

[72] Tabrizi SJ, Langbehn DR, Leavitt BR, Roos RA, Durr A, Craufurd D, Kennard C, Hicks SL, Fox NC, Scahill RI, Borowsky B, Tobin AJ, Rosas HD, Johnson H, Reilmann R, Landwehrmeyer B, Stout JC; TRACK-HD investigators. Biological and clinical manifestations of Huntington's disease in the longitudinal TRACK-HD study: Cross-sectional analysis of baseline data. Lancet Neurol. 2009;8:791801.

[73] Tabrizi SJ, Scahill RI, Durr A, Roos RA, Leavitt BR, Jones R, Landwehrmeyer GB, Fox NC, Johnson H, Hicks SL, Kennard C, Craufurd D, Frost C, Langbehn DR, Reilmann R, Stout JC; TRACK-HD Investigators. Biological and clinical changes in premanifest and early stage Huntington's disease in the TRACK- HD study: The 12-month longitudinal analysis. Lancet Neurol. 2011;10:31-42.

[74] Van den Bogaard SJ, Dumas EM, Acharya TP, Johnson H, Langbehn DR, Scahill RI, Tabrizi SJ, van Buchem MA, van der Grond J, Roos RA; TRACK-HD Investigator Group. Early atrophy of pallidum and accumbens nucleus in Huntington's disease. J Neurol. 2011;258:412-20.

[75] Petersen A, Gabery S. Hypothalamic and limbic system changes in Huntington's disease. Journal of Huntington's disease 2012;1:13-24.

[76] Tabrizi SJ, Reilmann R, Roos RA, Durr A, Leavitt B, Owen G, Jones R, Johnson H, Craufurd D, Hicks SL, Kennard C, Landwehrmeyer B, Stout JC, Borowsky B, Scahill RI, Frost C, Langbehn DR; TRACK-HD investigators. Potential endpoints for clinical trials in premanifest and early Huntington's disease in the TRACK-HD study: Analysis of 24 month observational data. Lancet Neurol. 2012;11:42-53.

[77] Dogan I, Eickhoff, SB, Schulz JB, Shah NJ, Laird AR, Fox PT, Reetz K. Consistent neurodegeneration and its association with clinical progression in Huntington's disease: A coordinate-based meta-analysis. Neurodegener Dis. 2012;DOI: $10.1159 / 000339528$.

[78] Beste C, Saft C, Yordanova J, Andrich J, Gold R, Falkenstein M, Kolev V. Functional compensation or pathology in cortico-subcortical interactions in preclinical Huntington's disease? Neuropsychologia. 2007;45:2922-30.

[79] Paulsen JS (2009) Functional imaging in Huntington's disease. Exp Neurol. 2009;216:272-77.
[80] Nguyen L, Bradshaw JL, Stout JC, Croft RJ, GeorgiouKaristianis N. Electrophysiological measures as potential biomarkers in Huntington's disease: Review and future directions. Brain Res Rev. 2010;64:177-94.

[81] Oppenheimer SM, Wilson JX, Guiraudon C, Cechetto DF. Insular cortex stimulation produces lethal cardiac arrhythmias: A mechanism of sudden death? Brain Res. 1991;550: 115-21.

[82] Tokgözoglu SL, Batur MK, Top uoglu MA, Saribas O, Kes S, Oto A. Effects of stroke localization on cardiac autonomic balance and sudden death. Stroke 1999;30:1301-11.

[83] Abboud H, Berroir S, Labreuche J, Orjuela K, Amarenco $\mathrm{P}$. Insular involvement in brain infarction increases risk for cardiac arrhythmia and death. Ann Neurol. 2006;59:691-99.

[84] Oppenheimer SM, Cechetto DF. Cardiac chronotropic organization of the rat insular cortex. Brain Res. 1990;533:66-72.

[85] Zamrini EY, Meador KJ, Loring DW, Nichols FT, Lee GP, Figueroa RE, Thompson WO. Unilateral cerebral inactivation produces differential left/right heart rate responses. Neurology 1990;40:1408-11.

[86] Oppenheimer SM, Kedem G, Martin WM. Left-insular cortex lesions perturb cardiac autonomic tone in humans. Clin Auton Res. 1996;6:131-40.

[87] Oppenheimer SM. Cerebrogenic cardiac arrhythmias: Cortical lateralization and clinical significance. Clin Auton Res. 2006;16:6-11.

[88] Macey PM, Wu P, Kumar R, Ogren JA, Richardson HL, Woo MA, Harper RM. Differential responses of the insular cortex gyri to autonomic challenges. Auton Neurosci. 2012;168:72-81.

[89] Thieben MJ, Duggins AJ, Good CD, Gomes L, Mahant N, Richards F, McCusker E, Frackowiak RS. The distribution of structural neuropathology in pre-clinical Huntington's disease. Brain 2002;125:1815-28.

[90] Kassubek J, Juengling FD, Kioschies T, Henkel K, Karitzky J, Kramer B, Ecker D, Andrich J, Saft C, Kraus P, Aschoff AJ, Ludolph AC, Landwehrmeyer GB. Topography of cerebral atrophy in early Huntington's disease: A voxel based morphometric MRI study. J Neurol Neurosurg Psychiatry. 2004;75:213-20.

[91] Douaud G, Gaura V, Ribeiro MJ, Lethimonnier F, Maroy R, Verny C, Krystkowiak P, Damier P, Bachoud-Levi AC, Hantraye P, Remy P. Distribution of grey matter atrophy in Huntington's disease patients: A combined ROI-based and voxel-based morphometric study. Neuroimage 2006;32: 1562-75.

[92] Yang AC, Chen TJ, Tsai SJ, Hong CJ, Kuo CH, Yang $\mathrm{CH}$, Kao KP. BDNF Val66Met polymorphism alters sympathovagal balance in healthy subjects. Am J Med Genet B Neuropsychiatr Genet. 2010;153:1024-30.

[93] Altar CA, Cai N, Bliven T, Juhasz M, Conner JM, Acheson AL, Lindsay RM, Wiegand SJ. Anterograde transport of brain-derived neurotrophic factor and its role in the brain. Nature 1997;389:856-60.

[94] Hofer M, Paglisui SR, Hohn A, Leibrock J, Barde YA Regional distribution of brain-derived neurotrophic factor mRNA in the adult mouse brain. EMBO J. 1990;9:2459-64.

[95] Yan Q, Radeke MJ, Matheson CR, Talvenheimo J, Welcher AA, Feinstein SC. Immunocytochemical localization of TrkB in the central nervous system of the adult rat. J Comp Neurol. 1997;378:135-57.

[96] Schober A, Wolf N, Huber K, Hertel R, Krieglstein K, Minichiello L, Kahane N, Widenfalk J, Kalcheim C, Olson L, Klein R, Lewin GR, Unsicker K. TrkB and neurotrophin 4 are important for development and maintenance of sym- 
pathetic preganglionic neurons innervating the adrenal medulla. J Neurosci. 1998;18:7272-84.

[97] Clark CG, Hasser EM, Kunze DL, Katz DM, Kline DD. Endogenous brain-derived neurotrophic factor in the nucleus tractus solitarius tonically regulates synaptic and autonomic function J Neurosci. 2011;31:12318-29.

[98] Okada S, Yokoyama M, Toko H, Tateno K, Moriya J, Shimizu I, Nojima A, Ito T, Yoshida Y, Kobayashi Y, Katagiri H, Minamino T, Komuro I. Brain-derived neurotrophic factor protects against cardiac dysfunction after myocardial infarction via a central nervous system-mediated pathway. Arterioscler Thromb Vasc Bio. 2012;32:1902-09.

[99] Zuccato C, Ciammola A, Rigamonti D, Leavitt BR, Goffredo D, Conti L, MacDonald ME, Friedlander RM, Silani V, Hayden MR, Timmusk T, Sipione S, Cattaneo E. Loss of huntingtin-mediated BDNF gene transcription in Huntington's disease. Science 2001;293:493-98.

[100] Zuccato C, Marullo M, Conforti P, MacDonald ME, Tartari M, Cattaneo E. Systematic assessment of BDNF and its receptor levels in human cortices affected by Huntington's disease. Brain Pathol. 2008;18:225-38.

[101] Gambazzi L, Gokce O, Seredenina T, Katsyuba E, Runne H, Markram H, Giugliano M, Luthi-Carter R. Diminished activity-dependent brain-derived neurotrophic factor expression underlies cortical neuron microcircuit hypoconnectivity resulting from exposure to mutant huntingtin fragments. J Pharmacol Exp Ther. 2010;335:13-22.

[102] Gharami K, Xie Y, An JJ, Tonegawa S, Xu B. Brainderived neurotrophic factor over-expression in the forebrain ameliorates Huntington's disease phenotypes in mice. J Neurochem. 2008;105:369-79.

[103] Paulsen JS, Ready RE, Hamilton JM, Mega M, Cummings J. Neuropsychiatric aspects of Huntington's disease. J Neurol Neurosurg Psychiat. 2001;71:310-14.

[104] Van Duijn E, Kingma EM, van der Mast RC. Psychopathology in verified Huntington's disease gene carriers. J Neuropsychiatry Clin Neurosci. 2007;19:441-48.

[105] Taggart P, Boyett MR, Logantha S, Lambiase PD. Anger, emotion and arrhythmias: From brain to heart. Front Physiol. $2011 ; 2: 67-74$.

[106] Nemeroff CB, Goldschmidt-Clermont PJ. Heartache and heartbreak-the link between depression and cardiovascular disease. Nat Rev Cardio. 2012;9:526-39.

[107] Leung YW, Flora DB, Gravely S, Irvine J, Carney RM, Grace SL. The impact of premorbid and postmorbid depression onset on mortality and cardiac morbidity among patients with coronary heart disease: Meta-analysis. Psychosom Med. 2012;74:786-801.

[108] Kemp AH, Quintana DS, Felmingham KL, Matthews S, Jelinek HF. Depression, Comorbid Anxiety Disorders, and Heart Rate Variability in Physically Healthy, Unmedicated Patients: Implications for Cardiovascular Risk. PLoS ONE 2012;7:e30777 doi: 10.1371/journal.pone.0030777.t002.

[109] Goldstein DS. Dysautonomia in Parkinson's disease: Neurocardiological abnormalities. Lancet Neurol. 2003;2: 669-76.

[110] Chaudhuri KR. Autonomic dysfunction in movement disorders. Curr Opin Neurol. 2001;14:505-511.

[111] Asahina M, Vichayanrat E, Low DA, Iodice V, Mathias CJ. Autonomic dysfunction in parkinsonian disorders: Assessment and pathophysiology. J Neurol Neurosurg Psychiat. 2012; doi:10.1136/jnnp-2012-303135.

[112] Jecmenica-Lukic M, Poewe W, Tolosa E, Wenning GK. Premotor signs and symptoms of multiple system atrophy. Lancet Neurol. 2012;11:361-68.
[113] Idiaquez J, Roman GC. Autonomic dysfunction in neurodegenerative dementias. J Neurol Sci. 2011;305:22-27.

[114] Goldstein DS. Cardiac ectopy in chronic autonomic failure. Clin Auton Res. 2010;20:85-92.

[115] Oka H, Toyoda C, Yogo M, Mochio S. Cardiovascular dysautonomia in de novo Parkinson's disease without orthostatic hypotension. Eur J Neurol. 2010;18:286-92.

[116] Bennett DA, Beckett LA, Murray AM, Shannon KM, Goetz CG, Pilgrim DM, Evans DA. Prevalence of parkinsonian signs and associated mortality in a community population of older people. N Engl J Med. 1996;33:471-76.

[117] Ben-Shlomo Y, Marmot MG. Survival and cause of death in cohort patients with parkinsonism: Possible clues to aetiology? J Neurol Neurosurg Psychiat. 1995;58:293-99.

[118] Szili-Török T, Kálmán J, Paprika D, Dibó G, Rózsa Z, Rudas L. Depressed baroreflex sensitivity in patients with Alzheimer's and Parkinson's disease. Neurobiol Aging. 2001;22:435-438.

[119] Furushima H, Niwano S, Chinushi M, Yamaura M, Taneda K, Washizuka T, Aizawa Y. Effect of atropine on QT prolongation and torsade de pointes induced by intracoronary acetylcholine in the long QT syndrome. Am J Cardiol. 1999;83:714-18.

[120] Castellanos A, Moleiro F, Lopera G, Huikuri H, Interian A Jr, Myerburg RJ. Dynamics of the uncorrected QT interval during vagal-induced lengthening of RR intervals. Am J Cardiol. 2000;86:1390-92.

[121] Farkas A, Dempster J, Coker SJ. Importance of vagally mediated bradycardia for the induction of torsade de pointes in an in vivo model. Br J Pharmacol. 2008;154:958-70.

[122] Grace AA, Roden DM. Systems biology and cardiac arrhythmias. Lancet 2012;380:1498-1508.

[123] Roden DM. Long-QT syndrome. N Engl J Med. 2008;358:169-76.

[124] Fossa AA, Wisialowski T, Crimin K. QT prolongation modifies dynamic restitution and hysteresis of the beat-to-beat QT-TQ interval relationship during normal sinus rhythm under varying states of repolarization. J Pharmacol Exp Ther. 2006;316:498-506.

[125] Yap YG, Camm AJ. Drug induced QT prolongation and torsades de pointes. Heart 2003;89:1363-72.

[126] Brodde OE, Bruck H, Leineweber K, Seyfarth T. Presence, distribution and physiological function of adrenergic and muscarinic receptor subtypes in the human heart. Bas Res Cardiol. 2001;96:528-38.

[127] Kawano H, Okada R, Yano K. Histological study on the distribution of autonomic nerves in the human heart. Heart Vessels 2003;18:32-39.

[128] Osuala K, Telusma K, Khan SM, Wu S, Shah M, Baker C, Alam S, Abukenda I, Fuentes A, Seifein HB, Ebert SN. Distinctive Left-Sided Distribution of Adrenergic-Derived Cells in the Adult Mouse Heart. PLoS ONE 2001;6:e22811.

[129] Houmsse M, Tyler J, Kalbfleisch S. Supraventricular tachycardia causing heart failure. Curr Opin Cardiol. 2011;26:261-69.

[130] Abboud FM. The Walter B. Cannon Memorial Award Lecture, 2009. Physiology in perspective: The wisdom of the body. In search of autonomic balance: The good, the bad, and the ugly. Am J Physiol Regul Integr Comp Physiol. 2010;298:R1449-67.

[131] Curtis MJ, Hancox JC, Farkas A, Wainwright CL, Stables CL, Saint DA, Clements-Jewery H, Lambiase PD, Billman GE, Janse MJ, Pugsley MK, Ng GA, Roden DM, Camm AJ, Walker MJ. The Lambeth Conventions (II): Guidelines for the study of animal and human ventricular and supraventricular arrhythmias. Pharmacol Ther. 2013;139:213-48. 